\title{
The Effect of Synchronous and Asynchronous Language Learning: A Study of Iranian EFL Intermediate Students' Vocabulary Learning
}

\author{
Ahmad Reza Lotfi \\ Islamic Azad University, Khorasgan Branch, Iran \\ Sayed Mir Hossein Hosseini Pozveh \\ University of Canterbury, Christchurch, New Zealand
}

\begin{abstract}
Synchronous learning and asynchronous learning are the two main approaches to teaching available in distance education. The main objective of the study was to determine which approach to vocabulary learning, would facilitate vocabulary learning more for Iranian EFL learners. From among the targeted population of 82 intermediate students of an English institute in Isfahan, Iran, students between the ages of 12 to 18, a sample of 60 students were chosen based on their score on a quick placement test (QPT). The selected participants undertook a vocabulary pre-test and were divided into two groups of 30 who in terms of language proficiency and vocabulary knowledge were homogenized. Both synchronous and asynchronous groups were taught "Advanced Vocabulary and Idiom", by the same teacher at one particular institute. In the period of 10 sessions of a semester, the synchronous groups were taught the vocabulary items in class synchronously and the asynchronous group was taught via email. After the post-test, the results with the t-test observed, indicated a significance difference between synchronous and asynchronous groups, p-value of .003 , gender with the pvalue of 0.027 and pre-test and post-test with the $p$-value of 0.047 , but no significance was observed for age with the p-value of 0.127 . The post-test results indicated that the synchronous group considerably outperformed the asynchronous group in the vocabulary knowledge they attained.
\end{abstract}

Index Terms-distance education, synchronous, asynchronous, English as a Foreign Language (EFL), vocabulary learning, social interaction

\section{INTRODUCTION}

In all methods of instruction that have been used in language teaching, they have all considered synchronous teaching as their base. In recent decades with the invention of computers and the virtual world, teaching has faced a new perspective. Teaching does not have to be done in classroom environments with desks, chairs and blackboards; it can be done in peoples rooms, behind their personal computers millions of miles away. This led to the asynchronous way of teaching, in which there is a time interval between teaching and learning. Though this has also become synchronous with the use of virtual applications that you can use live connections with, that is more like classroom instruction (Bernard et al, 2004, p. 409).

One of the most decisive impediments has been the deficiency of research on these synchronous and asynchronous approaches to teaching school ages in DE. Most research on DE in schools has been done in the United States; meanwhile researchers globally have also gradually shifted towards DE in schools (Barbour \& Stewart, 2008). With respect to scheduling, environment of learning and individual concentrated asynchronous DE had more adaptability than synchronous DE (Bernard et al, 2004, p. 408). Specialists presumed that 'for younger learners, the structure of synchronous DE may be better suited to their academic schedules and their need for spontaneous guidance and feedback' (p. 409).

The absence of teachers in asynchronous learning networks (ALN) leads to many issues. In the transition of face-toface instruction to ALN instruction this can cause many obstacles as Harasim et al. (1995) and Ory and Bullock (1997) indicated learners specially mention the non-availability of teachers and classmates physically the essential cause of concern. Kay (2006) in the meantime investigated various researches that undertook the assumption that attending AOD assists the progress of learning in which only one reported a noticeable difference in learning.

In the significance of having more accomplishment and mentality result, Bernard et al (2004) decided learners would function finer in asynchronous situations in contrast to synchronous situations. In spite of the fact that in asynchronous approach degrees of consistency were lower and dropout were significantly higher in contrast to synchronous DE notwithstanding the advantageous impacts. Both synchronous and asynchronous teaching functioned superior with specific approaches, synchronous implemented better altogether with media and teaching method was more excelling with asynchronous DE. Taking everything into account, it was resolved that synchronous DE defined 'a poorer-quality replication of classroom instruction' (p. 408) 
Advancing vocabulary acquisition can be acquired by having insight into the different effects of synchronous and asynchronous approaches and selecting the relevant approach of instruction. Absence of knowledge in this area could lead to time being wasted on experimenting different approaches and getting dissatisfied results (Wilkens, 1972). Today people are faced with shortage of time and getting dissatisfying outcomes is considered a waste of time for them. To satisfy their needs the products and outcomes of the research would facilitate learners in selecting an appropriate approach.

Flaw in English vocabulary can lead to a great deal of limitations for people who have to live in a society where English is a tool for many tasks and exchanging information. Despite the fact that vocabulary is only one component of English syllabus, having a lack in vocabulary generates serious issues, affecting language learners' performances in other areas such as reading, listening, speaking, and writing (Laufer, 1992; Laufer and Goldstein, 2004; Albrechtsen, Haastrup, and Henriken, 2008). Adequate vocabulary knowledge is also an indispensable component of effective test performance in different areas of language learning. It has been proved that language ability is to a large extent a function of vocabulary, and also results in exceed of listening, writing and reading (Alderson, 2005). In contrast with listening, writing and speaking, vocabulary is more applicable to be taught synchronously and asynchronously. It can be taught in class synchronously and taught through mailing asynchronously to students. Also assessing and rating the effects of learning can easily be computed.

The present study addresses the use of synchronous and asynchronous as an alternative approach on boosting vocabulary achievement of Iranian intermediate learners. The study is of significance as the impact of synchronous and asynchronous approaches on increasing vocabulary achievement has been rarely explored by the researchers and has not investigated in Iran. To put it simply, this study determines whether the asynchronous and synchronous approaches have any significant impact on intermediate EFL learners' vocabulary achievement or not. The findings are of benefit for language teachers to tailor the most effective teaching approaches to improve vocabulary achievement of language learners.

Meanwhile most researches have worked on policies and technologies, in which here we investigate the procedure in applying the approaches. In addition most studies have compared the influence to class practices but this study surveys design and delivery. Many studies pursued the effectiveness of learning technologies but failed to prove in which it is investigated in the current study. As it has also been mentioned, most studies on AOD concentrated on benefits and pitfall in which the present study links AOD with learning. It was asserted that each approach functions more convenient with specific methods but as Iran is a developing country this can vary and is of concern.

The research results can help educators and researchers of distance education understand better the types of instructional design that match with the different modes of distance-learning systems, provide recommendations to system developers on the improvement of the interface design of learning environments, and further the understanding of distance learners' online behaviors. In Iran a small amount of research has focused on this issue. Researchers claim that the structure of synchronous DE is more suitable for young learners as it best applicable for their schedule, guidance and feedback as many have mentioned the physical non-availability of instructors as a concern. School aged students have been investigated in the United States but have not been researched in Iran to find the more convenient approach of instruction. This has made the research a significant and important line to work on. The questions raised here are:

1. To what extent does synchronous teaching help learners improve their vocabulary?

2. To what extent does asynchronous teaching help learners improve their vocabulary?

3. Does synchronous teaching significantly differ from asynchronous teaching in helping learners improve their vocabulary?

\section{METHOdOLOGY}

\section{Participants}

The population of this study was of available subjects with the qualities needed in order to carry out the study. The available subjects of the study were Iranian EFL learners with Farsi as their mother tongue in an Isfahan language institute. The institute selected contained learners with the intermediate level, classes with both gender groups and students from the age range of 12 to 18 that were taught by the same instructor.

The total number of participants consisted of 82 intermediate students of both genders that were divided to two gender mixed classes. Class number one included 41 participants of whom 24 were male and 17 were female. The number two class was also comprised of 41 participants, 24 male and 17 female. To be ensured of their language proficiency level a quick placement test (QPT) was taken from all the participants. The result of the QPT indicated that 13 males and nine females in total did not qualify as intermediate and therefor were eliminated from the survey and their findings were not considered though still participated.

The 60 remaining participants in the study included 35 male and 25 female language learners. Specifically in class one, five male students and six female students were eliminated, leaving 19 male and 11 female applicable participants, and in class two, eight male and three female participants were eliminated remaining 16 male and 14 female participants. In total group one included of 30 participants which was randomly selected as the synchronous group and group two included of 30 participants and was assigned as the asynchronous group. 


\section{Instruments}

In order to convey the study a quick placement test (QPT) (see the appendix), 60 item four point test was attained to establish participants' language proficiency level. For the treatment of the study, 10 parts of “Advance Vocabulary and Idiom" was chosen. The advance level of the book was selected so that the participants would not be familiar with the vocabularies. To evaluate students' knowledge of the vocabulary, a 106 item four point pre-test (see the appendix) from 10 sections of the book was designed. After a pilot study had been carried out on the test, the validity was approved by an expert and the reliability was determined, the test was given to all the participants. In order to teach class one synchronously access to a classroom asides having the book itself was needed. For class two, to teach asynchronously access to the PDF format of the book, internet and email was of need. With regard to evaluating the treatment, a 106 item four point post-test (see the appendix) that was a rearranged form of the pre-test was administrated to the participants.

\section{Experimental Treatments}

The quasi-experimental research design that was in line with this research was selected and available subjects were used in order for the research to be carried out. A language institute in the city province of Isfahan with the intermediate proficiency level, Iranian ethnicity, Farsi as native language, mixed gender classes, taught by the same instructor and an age range from 12 to 18 was chosen. The language institute consisted of 82 participants that were split into two classes of 41, each seating 24 male and 17 female students. To be ensured of all the participants' language proficiency a QPT consisting of 60 items was taken from all the students. The results of the test indicated that 22, 13 male and nine female students did not qualify as intermediate language proficiency level. These students were eliminated from the study though still participated. From the 35 male and 25 female students left in the study, 19 male and 11 female were class one and 16 male and 14 female were class two. Each class consisted of 30 participant of which class one was selected as the synchronous class and class two was selected as the asynchronous class.

As it has been mentioned by National Reading Panel (2000) explicit teaching of vocabulary is more effective, in this case we taught the vocabulary explicitly. Before starting the research all students of both groups were asked about their knowledge of CALL, synchronous and asynchronous learning. Additionally the students of both synchronous and asynchronous groups were informed about the procedure they were going to be put through and the methodologies used so that they would be familiar with the study and understand the importance of the research (Cunningham, 2001).

\section{Synchronous Class}

The synchronous class that was also named class one was taught the book in the classroom. The classes were held two times a week on Saturdays and Tuesdays from six in the afternoon to half past seven in the afternoon. Each session one section of the book was taught to the students which expanded for 10 sessions over the course of five weeks. In the asynchronous class the students were taught the vocabulary, read the scripts and asked their questions at the same time.

\section{Asynchronous Class}

The asynchronous class also known as class number two was taught through email with the use of the PDF format of the book. The classes were held two times a week on Saturdays and Tuesdays by the instructor emailing the students each section of the book at five in the afternoon also containing guidance on the section. The students unlike class one had time till the next session to ask their questions on the selected section. This procedure took 10 sessions over the course of five weeks.

\section{Data Collection Procedure}

The book selected to teach vocabulary was "Advanced Vocabulary and Idioms". A pre-test of the vocabulary items of the book was designed which was at first handed out as a pilot study in order to establish its validity and reliability. After in the pilot study the validity and the reliability were affirmed, a 106 item four point scale test was designed and given to both classes. The test also included questions about students' names, age, sex, ethnic group and email address.

After teaching of the whole sections was completed, a post-test which was a reorganized form of the pre-test was taken from both classes. The passage of more than a month was considered convenient for students to not remember the questions. Students of both classes were asked to come to the institute on the same day and time which the post-test was handed to them and the results were gained.

\section{Data Analysis Procedure}

In analyzing the data, independent t-test averages of both groups was calculated and in case of a significant difference the effectiveness of each procedure was presumed. These differences based on demographic variables (sex, age, group and pre-test) was also calculated and analyzed. To test the variables normality of the study, the KolmogorovSmirnova and Shapiro-Wilk were used. In order to statistically analyze the effect and relation of the independent variables as group, sex, age and pre-test on the post-test, t-tests were used.

\section{RESULTS}

\section{Descriptive statistics}

Initially in order to achieve a quick overview of the results, descriptive statistics of data is observed. Table 4.1 shows the minimum, maximum, mean and standard deviation of the QPT, pre-test and post-test in separate groups and also for the entire observation regardless of their group (Total). According to table 4.1, the mean scores obtained in the pre-test score of synchronous group was (35.97) and of asynchronous group was (39.90), the mean post-test score obtained in 
synchronous group was (71.47) and in asynchronous group was (59.93). In addition the mean QPT score of synchronous group was (43.58) and in asynchronous group was (43.14). To assess the significance of these differences statistical analysis was used to analyze the data.

TABLE 4.1

DESCRIPTIVE STATISTICS

\begin{tabular}{|c|c|c|c|c|c|c|}
\hline Group & Descriptive statistics & QPT & Pre_Test & Post_Test & Age & Difference \\
\hline \multirow{5}{*}{ SYN } & $\mathrm{N}$ & 30 & 30 & 30 & 30 & 30 \\
\hline & Minimum & 40 & 10 & 39 & 12 & 4 \\
\hline & Maximum & 47 & 51 & 106 & 18 & 79 \\
\hline & Mean & 43.58 & 35.97 & 71.47 & 15.15 & 35.50 \\
\hline & Std. Deviation & 1.78 & 9.16 & 19.65 & 1.21 & 21.45 \\
\hline \multirow{5}{*}{ ASY } & $\mathrm{N}$ & 30 & 30 & 30 & 30 & 30 \\
\hline & Minimum & 40 & 24 & 25 & 12 & -12 \\
\hline & Maximum & 47 & 58 & 102 & 18 & 67 \\
\hline & Mean & 43.14 & 39.90 & 59.93 & 15.23 & 20.03 \\
\hline & Std. Deviation & 2.06 & 10.19 & 20.69 & 1.45 & 18.77 \\
\hline \multirow{5}{*}{ Total } & $\mathrm{N}$ & 60 & 60 & 60 & 60 & 60 \\
\hline & Minimum & 40 & 10 & 25 & 12 & -12 \\
\hline & Maximum & 47 & 58 & 106 & 18 & 79 \\
\hline & Mean & 43.36 & 37.94 & 65.70 & 15.19 & 27.76 \\
\hline & Std. Deviation & 1.92 & 9.81 & 20.84 & 1.33 & 21.45 \\
\hline
\end{tabular}

Figure 4.1 shows the trend of the pre-test and post-test scores to illustrate the differentiation of the two groups. Accordingly, as can be observed scores of the synchronous group have had a sharper increase in comparison to the asynchronous group. In simple terms, there has been more change in the pre-test and the post-test scores of the synchronous group.

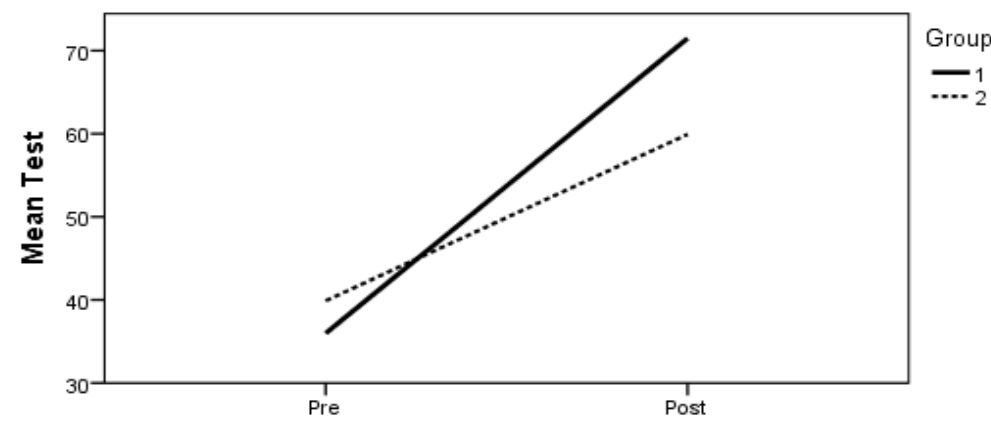

Figure 4.1 Trend of the Pre-Test and Post-Test Scores to Illustrate the Differentiation of the Two Groups Note. Group 1 is synchronous and group 2 is asynchronous

Table 4.2 illustrates the results of the QPT scores in two groups according to sex. According to the results of table 4.2, the mean scores do not show a considerable difference between the sexes in both groups, they were tested.

TABLE 4.2

QPT DESCRIPTIVE STATISTIC

\begin{tabular}{|c|c|c|c|c|c|c|}
\hline Group & sex & $\mathbf{N}$ & Minimum & Maximum & Mean & Std. Deviation \\
\hline \multirow{3}{*}{ SYN } & FEM & 11 & 43 & 47 & 44.81 & 1.08 \\
\hline & MAL & 19 & 40 & 46 & 42.87 & 1.74 \\
\hline & Total & 30 & 40 & 47 & 43.58 & 1.79 \\
\hline \multirow{3}{*}{ ASY } & FEM & 14 & 40 & 46 & 42.86 & 1.95 \\
\hline & MAL & 16 & 40 & 47 & 43.39 & 2.18 \\
\hline & Total & 30 & 40 & 47 & 43.14 & 2.06 \\
\hline \multirow{3}{*}{ Total } & FEM & 25 & 40 & 47 & 43.71 & 1.88 \\
\hline & MAL & 35 & 40 & 47 & 43.11 & 1.94 \\
\hline & Total & 60 & 40 & 47 & 43.36 & 1.92 \\
\hline
\end{tabular}

Table 4.3 examines the results of the pre-test scores in both groups, and in accordance to gender. In this table, the mean scores of the pre-test in both groups are homogenous for both genders. As a result the mean score obtained in the 
synchronous group for females was $(36.46 \pm 6.54)$ and for males $(35.69 \pm 10.54)$, also in the asynchronous group for females was $(38.79 \pm 8.72)$ and for males $(40.87 \pm 11.52)$. Furthermore the mean pre-test score regardless of group segregation, only encountering gender type, for females was $(37.77 \pm 7.77)$ slightly lower than males $(38.06 \pm 11.14)$.

TABLE 4.3

PRE-TEST DESCRIPTIVE STATISTIC

\begin{tabular}{|c|c|c|c|c|c|c|}
\hline Group & Sex & $\mathbf{N}$ & Minimum & Maximum & Mean & Std. Deviation \\
\hline \multirow{3}{*}{ SYN } & FEM & 11 & 24 & 42 & 36.46 & 6.54 \\
\hline & MAL & 19 & 10 & 51 & 35.69 & 10.54 \\
\hline & Total & 30 & 10 & 51 & 35.97 & 9.16 \\
\hline \multirow{3}{*}{ ASY } & FEM & 14 & 27 & 55 & 38.79 & 8.72 \\
\hline & MAL & 16 & 24 & 58 & 40.87 & 11.52 \\
\hline & Total & 30 & 24 & 58 & 39.90 & 10.19 \\
\hline \multirow{3}{*}{ Total } & FEM & 25 & 24 & 55 & 37.77 & 7.77 \\
\hline & MAL & 35 & 10 & 58 & 38.06 & 11.14 \\
\hline & Total & 60 & 10 & 58 & 37.94 & 9.81 \\
\hline
\end{tabular}

Table 4.4 presents the results of the two groups in regard to different genders. Based on the results of this table, the mean post-test score in both synchronous and asynchronous group for females is higher than males.

TABLE 4.4

POST-TEST DESCRIPTIVE STATISTIC

\begin{tabular}{|c|c|c|c|c|c|c|}
\hline Group & Sex & $\mathbf{N}$ & Minimum & Maximum & Mean & Std. Deviation \\
\hline \multirow{3}{*}{ SYN } & FEM & 11 & 46 & 106 & 77.42 & 17.82 \\
\hline & MAL & 19 & 39 & 105 & 68.02 & 20.29 \\
\hline & Total & 30 & 39 & 106 & 71.47 & 19.65 \\
\hline \multirow{3}{*}{ ASY } & FEM & 14 & 32 & 102 & 66.45 & 21.21 \\
\hline & MAL & 16 & 25 & 81 & 54.23 & 19.09 \\
\hline & Total & 30 & 25 & 102 & 59.93 & 20.70 \\
\hline \multirow{3}{*}{ Total } & FEM & 25 & 32 & 106 & 71.28 & 20.17 \\
\hline & MAL & 35 & 25 & 105 & 61.72 & 20.67 \\
\hline & Total & 60 & 25 & 106 & 65.70 & 20.84 \\
\hline
\end{tabular}

In table 4.5 examines the results of the pre-test scores in both groups, and in accordance to age. In this table, the mean scores of the pre-test in asynchronous group show a considerable difference between the genders. As a result the mean score obtained for females was (50.77 \pm ) and for males (41.64 \pm ). Furthermore the mean pre-test score regardless of group segregation, only encountering gender type, for code females was (40.03 \pm ) slightly higher than males (33.96 \pm ).

TABLE 4.5

\begin{tabular}{|c|c|c|c|c|c|c|}
\hline Group & Sex & $\mathbf{N}$ & Minimum & Maximum & Mean & Std. Deviation \\
\hline \multirow{3}{*}{ SYN } & FEM & 11 & 12 & 16 & 14.87 & 1.436 \\
\hline & MAL & 19 & 13 & 18 & 15.31 & 1.073 \\
\hline & Total & 30 & 12 & 18 & 15.15 & 1.213 \\
\hline \multirow{3}{*}{ ASY } & FEM & 14 & 14 & 18 & 15.66 & 1.000 \\
\hline & MAL & 16 & 12 & 17 & 14.86 & 1.701 \\
\hline & Total & 30 & 12 & 18 & 15.23 & 1.453 \\
\hline \multirow{3}{*}{ Total } & FEM & 25 & 12 & 18 & 15.31 & 1.248 \\
\hline & MAL & 35 & 12 & 18 & 15.10 & 1.392 \\
\hline & Total & 60 & 12 & 18 & 15.19 & 1.327 \\
\hline
\end{tabular}

Table 4.6 examines the results of the pre-test scores in both groups, and in accordance to various genders. In this table, the mean scores of the pre-test in asynchronous group show a considerable difference between the genders. As a

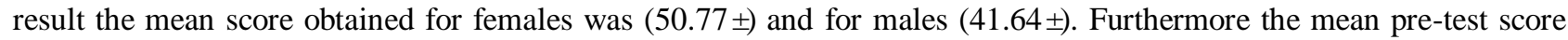
regardless of group segregation, only encountering gender type, for code females was (40.03 \pm ) slightly higher than males (33.96 $)$. 
TABLE 4.6

DIFFERENCE DESCRIPTIVE STATISTIC

\begin{tabular}{|c|c|c|c|c|c|c|}
\hline \multirow{2}{*}{ Group } & \multirow[b]{2}{*}{ sex } & \multirow{2}{*}{$\mathbf{N}$} & & \multirow[b]{2}{*}{ Std. Deviation } \\
\hline & & & Minimum & Maximum & Mean & \\
\hline \multirow{3}{*}{ SYN } & FEM & 11 & 5 & 73 & 40.97 & 17.379 \\
\hline & MAL & 19 & 4 & 79 & 32.33 & 23.336 \\
\hline & Total & 30 & 4 & 79 & 35.50 & 21.449 \\
\hline \multirow{3}{*}{ ASY } & FEM & 14 & 2 & 67 & 27.65 & 18.978 \\
\hline & MAL & 16 & -12 & 46 & 13.36 & 16.334 \\
\hline & Total & 30 & -12 & 67 & 20.03 & 18.768 \\
\hline \multirow{3}{*}{ Total } & FEM & 25 & 2 & 73 & 33.51 & 19.142 \\
\hline & MAL & 35 & -12 & 79 & 23.66 & 22.317 \\
\hline & Total & 60 & -12 & 79 & 27.76 & 21.449 \\
\hline
\end{tabular}

\section{Statistics analysis}

This section shows the relationships between variables with respect to the objectives of the study. Before performing the analysis five three are examined to assume the normality of QPT, the pre-test, post-test, age and difference (the difference of pre-test and post-test) score. The following table shows the test normality for all five variables. According to the results obtained for the p-value, all five variables have a normal distribution and the analysis of these three variables based on parametric tests is continued.

TABLE 4.7

TESTS OF NORMALITY

\begin{tabular}{|c|c|c|c|c|c|c|}
\hline \multirow{2}{*}{ Variable } & \multicolumn{3}{|c|}{ Kolmogorov-Smirnov $^{\mathrm{a}}$} & \multicolumn{3}{|c|}{ Shapiro-Wilk } \\
\hline & Statistic & df & Sig. & Statistic & df & Sig. \\
\hline QPT & .074 & 60 & $.200^{*}$ & .982 & 60 & .500 \\
\hline Pre_Test & .080 & 60 & $.200^{*}$ & .981 & 60 & .484 \\
\hline Post_Test & .064 & 60 & $.200^{*}$ & .979 & 60 & .389 \\
\hline Age & .109 & 60 & .074 & .970 & 60 & .147 \\
\hline Difference & .093 & 60 & .200 & .974 & 60 & .218 \\
\hline
\end{tabular}

\section{Variable QPT}

The first table in this section analyses the relation between QPT and the teaching groups. According to the normality of the QPT results an independent t-test was used to evaluate the relation (Table 4.8). According to $\mathrm{p}$-value $=0.378$ in this line the assumption of equality of variances for the two groups is accepted. In other words, the teaching groups have not had an impact on the QPT scores.

TABLE 4.8

BETWEEN GROUPS QPT DIFFERENCES IN THE INDEPENDENT T-TEST

\begin{tabular}{|c|c|c|c|c|c|c|c|}
\hline & \multicolumn{7}{|c|}{ t-test for Equality of Means } \\
\hline & \multirow{2}{*}{$\mathrm{t}$} & \multirow{2}{*}{ df } & \multirow{2}{*}{ p-value } & \multirow{2}{*}{ Mean Difference } & \multirow{2}{*}{$\begin{array}{l}\text { Std. Error } \\
\text { Difference }\end{array}$} & \multicolumn{2}{|c|}{$\begin{array}{l}\text { 95\% Confidence Interval of the } \\
\text { Difference }\end{array}$} \\
\hline & & & & & & Lower & Upper \\
\hline Equal variances & .889 & 58 & .378 & .44208 & .49721 & -.55320 & 1.43735 \\
\hline
\end{tabular}

Variable Pre-Test

Table 4.9 used t-test to determine and analyze the relationship between the pre-test and teaching groups. According to the table, there was no significant correlation between these two variables ( $\mathrm{p}$-value $=0.122$ ).

TABLE 4.9

BETWEEN GROUPS PRE-TEST DIFFERENCES IN THE INDEPENDENT T-TEST

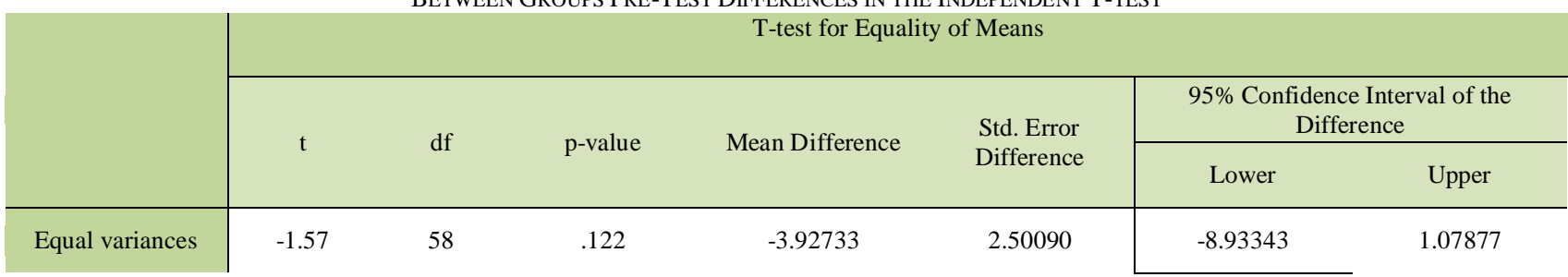




\section{Variable Post-Test}

In table 4.10 the relationship between test scores and teaching groups was evaluated. In this table there is a significant relationship between the two variables $(\mathrm{p}$-value $=0.031$ ). This means that the post-test score mean difference was 11.5 points more than the asynchronous group and this difference is statistically significant.

TABLE 4.10

BETWEEN GROUPS POST-TEST DIFFERENCES IN THE INDEPENDENT T-TEST

\begin{tabular}{|c|c|c|c|c|c|c|c|}
\hline & \multicolumn{7}{|c|}{ T-test for Equality of Means } \\
\hline & \multirow{2}{*}{$\mathrm{t}$} & \multirow{2}{*}{ df } & \multirow{2}{*}{ p-value } & \multirow{2}{*}{ Mean Difference } & \multirow{2}{*}{$\begin{array}{l}\text { Std. Error } \\
\text { Difference }\end{array}$} & \multicolumn{2}{|c|}{$\begin{array}{l}\text { 95\% Confidence Interval of the } \\
\text { Difference }\end{array}$} \\
\hline & & & & & & Lower & Upper \\
\hline Equal variances & 2.214 & 58 & .031 & 11.53839 & 5.21083 & 1.10779 & 21.96900 \\
\hline
\end{tabular}

\section{Variable Age}

Table 4.11 elaborates on the relationship between test scores and age. In this table there is no significant relationship between the two variables ( $\mathrm{p}$-value $=0.818$ ).

TABLE 4.11

BETWEEN GROUPS AGE DIFFERENCES IN THE INDEPENDENT T-TEST

\begin{tabular}{|c|c|c|c|c|c|c|c|}
\hline & \multicolumn{7}{|c|}{ T-test for Equality of Means } \\
\hline & \multirow{2}{*}{$\mathrm{t}$} & \multirow{2}{*}{ df } & \multirow{2}{*}{$\mathrm{p}$-value } & \multirow{2}{*}{ Mean Difference } & \multirow{2}{*}{$\begin{array}{l}\text { Std. Error } \\
\text { Difference }\end{array}$} & \multicolumn{2}{|c|}{$\begin{array}{l}\text { 95\% Confidence Interval of the } \\
\text { Difference }\end{array}$} \\
\hline & & & & & & Lower & Upper \\
\hline Equal variances & -.231 & 58 & .818 & -.080 & .345 & -.771 & .612 \\
\hline
\end{tabular}

\section{Variable Difference}

In the last table 4.12 the relationship between test scores and difference was evaluated. In this table there is a significant relationship between the two variables $(\mathrm{p}$-value $=0.004)$. This means that on average there is 15.46 points more and this difference was statistically significant.

TABLE 4.12

BETWEEN GROUP DIFFERENCE DIFFERENCES IN THE INDEPENDENT T-TEST

\begin{tabular}{|c|c|c|c|c|c|c|c|}
\hline & \multicolumn{7}{|c|}{ T-test for Equality of Means } \\
\hline & \multirow{2}{*}{$\mathrm{t}$} & \multirow{2}{*}{ df } & \multirow{2}{*}{ p-value } & \multirow{2}{*}{ Mean Difference } & \multirow{2}{*}{$\begin{array}{l}\text { Std. Error } \\
\text { Difference }\end{array}$} & \multicolumn{2}{|c|}{$\begin{array}{l}\text { 95\% Confidence Interval of the } \\
\text { Difference }\end{array}$} \\
\hline & & & & & & Lower & Upper \\
\hline Equal variances & 2.972 & 58 & .004 & 15.466 & 5.203 & 5.050 & 25.882 \\
\hline
\end{tabular}

The post-test scores

In table 4.13, the relationship between the scores of post-test with gender, group, pre-test and age were evaluated. Also in table 4.13 between post-tests and learning group variable ( $\mathrm{p}$-value $=0.003$ ) and also between post-test variable and gender $(\mathrm{p}$-value $=0.027)$, significant relationship was observed. In relation to the teaching groups and post-test scores synchronous group, on average, is about 15.4 units higher than asynchronous group with adjust or other variable. In addition on gender, the post-test scores for females are on average about 11.3 points higher than males with adjust or other variable.

TABLE 4.13

THE DifFERENCE BETWEen THE SCORES OF POST-Test WITH GENDER, Group, AGE AND PRE-TEST

\begin{tabular}{|c|c|c|c|c|c|}
\hline \multirow{2}{*}{ Parameter } & \multirow{2}{*}{ B } & \multirow{2}{*}{ Std. Error } & \multicolumn{2}{|c|}{ 95\% Wald Confidence Interval } & \multirow[b]{2}{*}{ p-value } \\
\hline & & & Lower & Upper & \\
\hline (Intercept) & -2.236 & 25.699 & -53.737 & 49.265 & .931 \\
\hline SYN & 15.417 & 5.020 & 5.358 & 25.477 & .003 \\
\hline ASY & $0^{\mathrm{a}}$ & . & . & . & . \\
\hline FEM & 11.302 & 4.967 & 1.348 & 21.257 & .027 \\
\hline MAL & $0^{\mathrm{a}}$ & . & . & . & . \\
\hline Age & 1.433 & .925 & -.421 & 3.287 & .127 \\
\hline Pre_Test & .520 & .256 & .008 & 1.033 & .047 \\
\hline
\end{tabular}


For the relation between post-test and age, on average it is 1.4 unites higher with the p-value of .127, no significant relation, with adjust or other variable. In addition in relation to pretest, post-test is .520 higher with the p-value of .047 , which there is a significant relation, with adjust or other variable.

For age the number and positive correlation needed for the increase of a year to the age of the students, 1.43 units are needed. Also there is a positive correlation between pre-test and post-test which means that on average the pre-test score on a pre-test increase of one unit adds .52 to the post-test. Figure 4.2 illustrates the mean scores in comparison to groups.

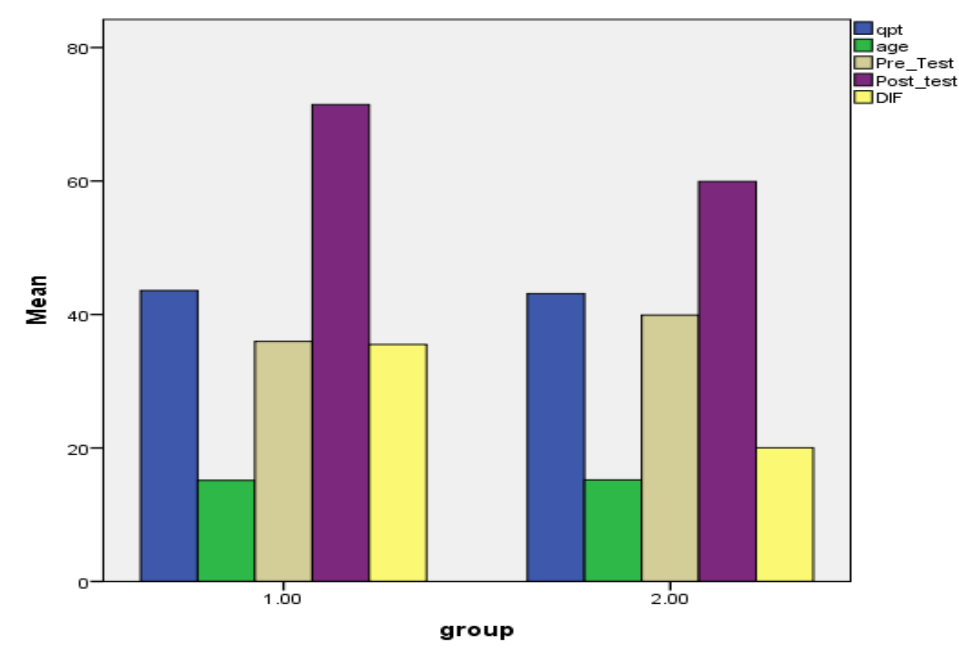

Figure 4.2 Mean Scores in Comparison to Groups

Note. Group 1 is synchronous and Group 2 is asynchronous

\section{DISCUSSION}

The first research question investigated the effect of synchronous teaching on the learning of vocabulary in Iranian EFL students. As mentioned before the synchronous group were given a pre-test and after a considerable amount of time after that they were taught the vocabulary items in the period of the semester, a post-test which was a reordered form of the pre-test. According to the results obtained through t-test statistical analyses with p-value of $0.003<0.05$, the first null hypothesis was accepted. The results of the statistical analyses proved that teaching vocabulary synchronously improves the vocabulary acquisition of EFL students.

The second research question analyzed the effect of asynchronous method on learning on Iranian EFL students' vocabulary learning. In this process the asynchronous group was also given a pre-test and a rearranged form for the post-test after a semester of which they were taught the vocabulary items. In correspondence with the results that were gathered through t-test statistical analyses with the p-value $0.003<0.05$, the second null hypothesis was also accepted. Results attained through statistical analyses approved that teaching vocabulary asynchronously also improves the vocabulary acquisition of EFL students.

The third research question elaborated on the difference of synchronous and asynchronous vocabulary learning of Iranian EFL learners. As mentioned after the pre-test was taken from both groups and the teaching of vocabulary a posttest was taken from them. Through t-test statistical analyses of the results with p-value $0.003<0.05$, the third null hypothesis was also accepted in the sense that there was a significance difference between synchronous and asynchronous learning of vocabulary. According to the results the synchronous group improved significantly in comparison to the asynchronous group.

The present research focused on vocabulary acquisition synchronously and asynchronously to investigate the base and most important step in language learning. As it has been affirmed vocabulary plays a vital role in language learning to extent where researchers claim that more knowledge of words has a direct influence on the results of languages and its exams (Laufer 1992; Laufer and Goldstein 2004; Alderson 2005; Albrechsen, Haastrup, and Henriken 2008).

As Iranian students have been proven to be more dependent learners, the instructional design should focus on customization, not standardization of content to move the learners' attention to its needs (Reigeluth, 1999). The implication of the results of the study is that it enables policy makers understand students more and select the most convenient method that learners' best adapt to. Synchronous and asynchronous methods are methods mainly used in vocabulary teaching of which the results of this research implicate that synchronous method for Iranian EFL learners is the most convenient. It can be appointed by this that Iranians are still dependent and using dependent procedures gets better results from them and also pointing out the needs in making Iranian teen students independent.

The lack and physical non-availability of the instructors in asynchronous teaching for students has been reported to be their main cause of concern (Harasim et al., 1995; Ory \& Bullock, 1997). The physical availability of instructor and classmates in the synchronous method is another reason for the more notable results. In the case of gender this could conclude that male students are more dependent in comparison to female students. To overcome this issue, instructional 
system designers have to focus on training/learning and decide which technology works more efficiently in certain environments (Him et al., 1999).

The confirmation of the results being that synchronous method had significant outcome as to asynchronous method, affirms that the time spent in classes and on tasks is more efficient (Chun, 1994; Kern, 1995). Applying too can be that for better empowerment, autonomy, equality, and enhancement of critical thinking skills synchronous applies (see Kroonenberg, 1994/1995; Warschauer, Turbee, \& Roberts, 1996). Howbeit Cummins and Sayers (1995) pointed out that asynchronous learning can too create opportunities in second language learning. Ironically Abrams (2003) states that in terms of having time to think, asynchronous method in comparison to synchronous method is more convenient by giving students time to think, have access to resources and planning their answers. In spite of this statement the result outcomes of the present study proved differently.

\section{CONCLUSION}

The Current research elaborated on the synchronous and asynchronous teaching of vocabulary as the main approaches to teaching in the world. Research was conducted on 60 Iranian EFL students between the ages of 12 to 18 with 25 males and 35 females, to evaluate which method would be most beneficial in the learning of vocabulary. The B. J. Thomas's “Advanced Vocabulary and Idiom” book was used to evaluate and teach vocabulary to the students. Two groups of 30 that were chosen were taught for 10 sessions in the period of a semester. The synchronous group was taught in class and the asynchronous group was taught by email. After the process of teaching was done a parallel form of the pretest was taken from both groups. The results of the posttest indicated that there was a considerable difference between both groups. In attaining better results the synchronous group outperformed the asynchronous group in learning vocabulary thus indicating that interaction and collaboration has a key role in the learning process.

\section{REFERENCES}

[1] Albrechtsen, D., Haastrup, K., \& Henriksen, B. (2008). Vocabulary and writing in a first and second language: Processes and development. Springer.

[2] Alderson, J. C. (2005). Assessing reading. Ernst Klett Sprachen. Cambridge University Press.

[3] Barbour, M. K., \& Stewart, R. (2008). A Snapshot State of the Nation Study: K-12 Online Learning in Canada. North American Council for Online Learning.

[4] Bernard, R. M., Abrami, P. C., Lou, Y., Borokhovski, E., Wade, A., Wozney, L., Wallet, P.A., Fiset, M. \& Huang, B. (2004). How does distance education compare with classroom instruction? A meta-analysis of the empirical literature. Review of educational research, 74(3), 379-439.

[5] Harasim, L. M., Hiltz, S. R., Teles, L., \& Turoff, M. (1995). Learning networks: A field guide to teaching and learning online. MIT press.

[6] Kay, R. H. (2006). Developing a comprehensive metric for assessing discussion board effectiveness. British Journal of Educational Technology, 37(5), 761-783.

[7] Laufer, B. (1992). How much lexis is necessary for reading comprehension?. In Vocabulary and applied linguistics (pp. 126132). Palgrave Macmillan UK.

[8] Laufer, B., \& Goldstein, Z. (2004). Testing vocabulary knowledge: Size, strength, and computer adaptiveness. Language Learning, 54(3), 399-436.

[9] Ory, J. C., \& Bullock, C. (1997, November). Student use of and attitudes about on-campus ALN. In Frontiers in Education Conference, 1997. 27th Annual Conference. Teaching and Learning in an Era of Change. Proceedings. (Vol. 1, pp. 416-431). IEEE.

[10] Wilkins, D. (1976). Notional syllabuses. Bulletin CILA (Commission interuniversitaire suisse de linguistique appliquée)(«Bulletin VALS-ASLA» depuis 1994), 24, 5-17..

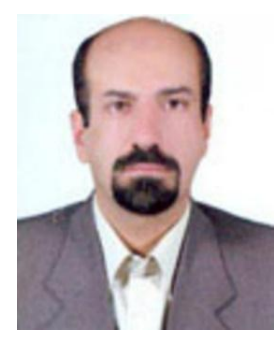

Ahmad Reza Lotfi: Dept. of English Language Islamic Azad University--Khorasgan (Isfahan) Branch, Isfahan, IRAN. TELEPHONE NUMBER: 00989133178603 E-MAIL: lotfi.ahmadreza@gmail.com DATE OF BIRTH: 6 Sept, 1965 PLACE OF BIRTH: Shahreza, Isfahan (IRAN) HIGHER EDUCATION 1992-1997 Received my Ph.D. in English Language Teaching (ELT) from Ph.D. Research Centre of Islamic Azad University in Tehran. I completed my doctoral dissertation entitled On the Significance of Negative Evidence in Second-Language Learning under the supervision of Dr. A. Miremadi. 


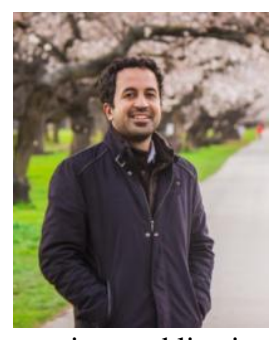

Sayed Mirhossein Hosseini Pozveh: Received his BACHELOR OF ARTS in 2013 in English Language and Literature from ISFAHAN UNIVERSITY, ISFAHAN, IRAN. He got his MASTER OF ARTS 2016 in

Teaching English as a Second Language (TEFL) from ISFAHAN AZAD UNIVERSITY, ISFAHAN, IRAN. $\mathrm{He}$ is a PHD candidate due to finish in 2020 in Teacher Education from the UNIVERSITY OF CANTERBURY, CHRISTCHURCH, NEW ZEALAND.

He has been an ESOL teacher both in Iran and New Zealand teaching various levels for over 8 years. Mir was a quantitative researcher with a focus on synchronous and asynchronous learning. Moving to qualitative research, the main focus of his $\mathrm{PhD}$ is on academic writing, learning communities, and agency of international postgraduate students. Further, he has received a STED scholarship from the University of Canterbury. His previous publications and conference presentations are:

Rajabi, B., Hosseini, M. "A Quantitative Analysis of Demotivating Factors for Iranian Intermediate High school EFL Learners" Published in Mediterranean Journal of Social Sciences.

Biria, R., Hosseini, M.*, and Rajabi, B. "Improving Oral Fluency of EFL Students with Different Proficiency Levels through Explicit Instruction of Face Threatening Strategies" English Language Teaching (ELT), Published in TPLS in October 2017.

Hosseini, M. "Improving academic writing: Self-efficacy and collaborative learning" ECER conference, Bolzano, Italy, September 2018

His main interest is to find ways that would deepen comprehension methods and ease learning for students and make studying pleasurable. 